\title{
The effects of therapeutic exercise on the balance of women with knee osteoarthritis: a systematic review
}

\section{Efeito de exercícios terapêuticos no equilíbrio de mulheres com osteoartrite de joelho: uma revisão sistemática}

Andressa Silva, Paula R. M. S. Serrão, Patrícia Driusso, Stela M. Mattiello

\begin{abstract}
Objective: The objective of this review was to examine evidence regarding the effects of therapeutic exercise on the balance of women with knee osteoarthritis (OA). Methods: The search was conducted in Pubmed, Medline, Lilacs, SciELO, ISI web of knowledge, PEDro and the Cochrane Collaboration. We used the keywords: "knee", "balance", "women" and "rehabilitation" in combination with "osteoarthritis". We selected randomized controlled clinical trials published in English, Portuguese and Spanish over the last 10 years. To verify the methodological quality of selected clinical trials, the PEDro Scale was applied. Results: A total of 20 studies were found in the electronic search. Of these, only 9 met the inclusion criteria and were analyzed in full. Eight of these 9 studies were classified as having high methodological quality on the PEDro Scale. Although the methods and interventions regarding balance varied widely in these studies, most found significant improvement in the balance of women with knee OA. Conclusion: Since the studies included in this systematic review were of high methodological quality, we can conclude that the therapeutic exercises they used improved the balance of women with knee OA.
\end{abstract}

Keywords: osteoarthritis; therapeutic exercises; postural balance; women's health; physical therapy.

\section{Resumo}

Objetivo: Fornecer evidências relacionadas ao efeito de exercícios terapêuticos sobre o equilíbrio de mulheres com osteoartrite $(\mathrm{OA})$ de joelho. Métodos: A busca foi realizada nas bases de dados Pubmed, Medline, Lilacs, SciELO, ISI web of knowledge, PEDro e Colaboração Cochrane. Foram utilizadas as palavras-chave: knee, balance, women, rehabilitation em combinação com osteoarthritis. Foram selecionados ensaios clínicos aleatórios e controlados dos últimos dez anos, em língua inglesa, portuguesa e espanhola. Para verificar a qualidade dos ensaios clínicos selecionados, aplicou-se a Escala PEDro. Resultados: Encontrou-se um total de 20 estudos a partir da busca eletrônica. Desses, apenas nove satisfizeram os critérios de inclusão e foram analisados integralmente. A avaliação da qualidade metodológica dos nove estudos incluídos permitiu classificar oito deles como de alta qualidade metodológica. Os métodos e as intervenções para o equilíbrio variaram amplamente, no entanto a maioria dos estudos encontrou melhora significativa no equilíbrio de mulheres com OA de joelho. Conclusão: Como os estudos incluídos nesta revisão sistemática têm uma alta qualidade metodológica, pode-se concluir que os exercícios terapêuticos utilizados pelos estudos melhoraram o equilíbrio de mulheres com OA de joelho.

Palavras-chave: osteoartrite; exercícios terapêuticos; equilíbrio postural; saúde da mulher; fisioterapia.

Received: 08/12/2010 - Revised: 02/14/2011 - Accepted: 07/18/2011

Physical Therapy Department, Universidade Federal de São Carlos (UFSCar), São Carlos, SP, Brazil

Correspondence to: Stela Márcia Mattiello, Departamento de Fisioterapia, Universidade Federal de São Carlos, Rodovia Washington Luis, Km 235, Caixa Postal 676, CEP 13565-905, São

Carlos, SP, Brasil, e-mail: stela@ufscar.br 


\section{Introduction $: \therefore$.}

Osteoarthritis (OA) is a chronic and degenerative disease characterized by pain and gradual loss of joint cartilage ${ }^{1-3}$. It has multifarious origins and may be present in various joints ${ }^{4}$, where biochemical, metabolic and morphological changes take place ${ }^{5}$. It is characterized by a loss of normal configuration, crackling during movement, bone deformities, the formation of bone spurs, the presence of inflammatory process ${ }^{6,7}$, the accumulation of synovial fluid, weakness of the quadriceps and sensorimotor loss ${ }^{5,8-13}$.

OA affects more than $80 \%$ of the population of older adults $^{9,10}$ with women affected more often than the men ${ }^{14}$, including a 35-45\% prevalence in those 65 years of age ${ }^{15}$. Srikanth et al. ${ }^{16}$ verified in a meta-analysis that women have a significantly higher risk of developing knee and hand OA than men.

Although the reasons for higher prevalence in women are not clear ${ }^{17}$, several factors can be cited: the hormonal, including post-menopausal, remodeling of cartilage ${ }^{18}$ (which occurs at around 50 years-old and is followed by decreasing levels of estrogen, a hormone that provides chondrial protection ${ }^{14,19,20}$ ), muscle weakness and poor lower limb alignment (of the femur in relation to the tibia) ${ }^{21}$, obesity ${ }^{22}$ and lower volumes of joint cartilage in women than $\operatorname{men}^{23}$.

OA affects joints that support weight unloading and, among them, the knee is the most affected ${ }^{16}$. Abnormal and excessive loads are important factors that can result in OA of the knee ${ }^{24}$, a joint whose function is essential in many activities of daily living (ADL) such as ascending and descending stairs, getting up from a chair and walking ${ }^{25}$.

Patients with knee OA show quadriceps muscle weakness as well as proprioceptive deficits ${ }^{3,5,9-11}$, which can alter balance and postural control ${ }^{3,8}$. The joint inflammation present in these patients contributes to pain and prevents the arrival of afferent information regarding movement and sense of joint position ${ }^{26}$. Such proprioceptive deficits cause a change in the dynamic stability provided by muscles around the joint, generating a functional instability that limits the individual's ability to perform $\mathrm{ADLs}^{26,27}$. A study using a force platform to measure the pressure of each portion of the foot in order to evaluate the static and dynamic balance of patients with grades I to IV knee OA demonstrated that the degree of knee OA was positively correlated with the length and width of oscillation, i.e., as the degree of OA increases, the greater the patient's difficulty in maintaining balance ${ }^{28}$.

Thus, in an attempt to minimize these effects in patients with OA, various therapeutic resources have been proposed in literature ${ }^{8,15,27,29}$. For most patients with OA, the recommendation is conservative treatment that helps reduce and relieve symptoms, improve performance of functional activities, prevent loss of muscle strength and slow the progression of the disease. Among the different conservative treatments, exercise has been shown to reduce pain and improve functional performance. There is already a good level of clinical evidence for the efficacy of aerobic exercise and strength training for knee $\mathrm{OA}^{13,30-33}$. However, few studies regarding the effects of exercise on the postural stability and balance of OA patients have been conducted ${ }^{8}$.

A significant improvement in balance has been found in a number of studies involving short-term exercise (6-16 weeks) ${ }^{34,35}$. In contrast, Crilly et al. ${ }^{36}$ found no significant balance improvement after a 12 week exercise program that had been specifically developed to improve balance in a group of elderly women.

Thus, since balance impairment is one of the first changes in patients with knee OA and results in compromised postural control, balance can be an important tool for monitoring OA patients and planning the most appropriate mode of therapeutic exercise for individuals with OA. This is especially true for women, since they are more affected.

In view of the need for further clarification about this issue, the purpose of this review was to provide clinical and scientific evidence on the efficacy of therapeutic exercise approaches for improving balance in women with knee OA.

\section{Methods : :}

\section{Search strategy}

Searches were carried out in the following electronic databases: Pubmed Medline, Lilacs, SciELO, ISI web of knowledge, PEDro and the Cochrane Collaboration.

The keywords used were: knee, balance, women, rehabilitation and osteoarthritis, linked by the boolean operator AND. The bibliographical survey was restricted to randomized and controlled clinical trials published in the last ten years (January/2000 - July/2010) in English, Portuguese or Spanish, involving individuals aged over 45 years.

Two evaluators (AS and PRMSS) independently selected the studies based on titles, excluding those that were not related to the theme of this review. After selection, the evaluators analyzed the abstracts of the selected articles to identify those that met the inclusion criteria. The included studies were analyzed in their entirety according to a structured script involving the following parameters: author/year, sample, study design, outcomes measured, intervention instruments and effects found. 


\section{Study selection}

\section{Type of study}

Only randomized controlled trials (RCTs) conducting interventions involving therapeutic exercise for balance in women with knee OA were selected.

\section{Type of participants}

Only studies that reported balance results for women with knee OA were selected.

\section{Type of interventions}

Only studies that investigated or compared therapeutic exercise interventions for improving balance in women with OA were selected.

\section{Type of outcome of interest}

Only studies whose main objective was to investigate the influence of therapeutic exercise on the variable 'balance' in patients with knee OA were included.

\section{Assessment of methodological quality}

The PEDro Scale ${ }^{37}$, which is based on the Delphi list ${ }^{38}$ and was translated into Portuguese in $2009^{39}$, was used to assess the methodological quality of the included studies. It consists of 11 items that assess the methodological quality of randomized clinical trials, and focuses on two aspects of the study: whether it has internal validity and whether it contains sufficient statistical information to make it interpretable. Only 10 of the 11 evaluated criteria were rated ${ }^{37}$. Each criterion is scored according to its presence or absence in the assessed study. The final score is obtained by the sum of all positive responses.

Studies with a score equal to or greater than $5(50 \%)$ were considered high quality, in accordance with Moseley et al. ${ }^{40}$. However, according to Maher ${ }^{41}$, due to the impossibility of achieving certain conditions, such as the blinding of therapists or subjects in intervention studies, the maximum achievable score for this type of study would be 8/10.

So, for this review, all randomized with a score greater than or equal to $5(5 / 8)$ were considered to be of high methodological quality.

The studies classified with the PEDro Scale were analyzed independently by two evaluators and, when there was divergence, the disparate items were reviewed and discussed with a third evaluator until consensus was reached.

\section{Data analyses}

A five-level scoring system was used to categorize the evidence in this review. The number, methodological quality and results of the studies involving a given variable were used to determine its level of evidence ${ }^{42,43}$.

Strong evidence was indicated by consistent findings in two or more high quality RCTs;

Moderate evidence was indicated by consistent findings in a high-quality RCT as well as one or more low-quality RTCs, or by consistent findings in multiple low-quality RTCs;

Limited evidence was indicated by a single RCT or multiple low-quality RCTs;

Conflicting evidence was indicated by inconsistent findings in multiple RCTs;

Absent evidence occurred in no RCTS.

\section{Results $: \therefore$.}

\section{Identified studies}

The initial search resulted in 20 articles. After the titles and abstracts, the studies appearing in more than one database or that did not meet predetermined inclusion criteria were excluded. The final selection, made by consensus, resulted in the inclusion of nine articles in the quality assessment phase.

Eleven articles were eliminated because they did not match the proposed theme, due either to the use of medications ${ }^{44-46}$, surgeries ${ }^{47,48}$, proprioceptive orthoses ${ }^{49}$ or to other exclusion criteria such as lack of a control group ${ }^{50-54}$.

\section{Assessment of study quality}

Among the nine articles evaluated on the PEDro Scale, eight scored greater than or equal to 5 and were thus considered high quality. The studies by Hinman, Heywood and Day ${ }^{27}$ and Lund et al. ${ }^{2}$ achieved the highest scores, with 8 points each. However, only Diracoglu et al. ${ }^{1}$ was considered to be of low quality (Table 1). When the studies were examined together, there was strong scientific evidence from high quality studies with consistent results ${ }^{8,13,15,27,29,55,56}$ that the balance of women with knee OA improved.

\section{General data about the selected articles}

To better describe the articles included in this review, they were summarized using information on the following topics: author/year, sample, design, outcomes measured, interventions, instruments and effects found (Table 2).

The types of therapeutic exercise used to improve balance in the selected clinical trials were: aerobic exercise and strength training ${ }^{1,8}$, Tai $\mathrm{Chi}^{56}$, hydrotherapy ${ }^{27}$, vibrating platform exercise ${ }^{29}$, balance exercises ${ }^{55}$, strength training 
with controlled or uncontrolled weights ${ }^{13}$ and educational programs ${ }^{15}$.

The sample size of the nine studies varied from 43 to 273 individuals with OA. In most studies ( $\mathrm{n}=5$ ), patients of both sexes participated. However, the protocols of four studies involved only women ${ }^{1,2,29,56}$. For the majority of the studies $(n=7)$, the clinical diagnosis of $\mathrm{OA}$, which was necessary for inclusion in the review, was according the criteria of the American College of Rheumatology (ACR).

All studies were experimental, with pre- and post-intervention assessments; long-term treatment evaluation (follow-up) occurred only in two studies ${ }^{2,27}$.

Regarding the effects found in the majority of the studies, there was significant balance improvement between pre-and-post intervention evaluations, with the exception of Lund et al. ${ }^{2}$.

\section{Discussion $: \because$.}

The analysis indicated that a variety of therapeutic exercises are used in clinical physical therapy practice with knee OA patients. Of the nine studies assessed on the PEDro Scale ${ }^{37}$, eight were considering to have high methodological quality.

It was observed that the therapeutic exercises used in the reviewed literature can be considered as treatment possibilities along with other existing methods (electro- thermo-phototherapy, cryotherapy, medications and psychotherapy) and, in order to achieve satisfactory results, should be used jointly to treat OA patients. The treatment proposals of the studies included in this systematic review were satisfactory not only regarding the therapeutic exercises used (physical exercise $e^{1,8,13,15}$ including aerobics and strength training ${ }^{2,27}$, hydrotherapy, kinesiotherapy ${ }^{56}$ and proprioceptive training ${ }^{29,55}$ ), but also with regarding methodological quality. However, it should be pointed out that only McKnight et al. ${ }^{15}$ observed a moderate effect size in the analyzed intra-group variables; the treatment effect size in the remaining studies was small $2,13,27$.

In the reviewed studies, only one found no balance improvement ${ }^{2}$ in OA patients treated for eight weeks. Holden et al.$^{57}$ reported that a time exceeding eight weeks is necessary for satisfactory balance results.

The methodological guidelines of the evaluated studies were properly prepared and described, allowing clinical reproducibility.

Regarding the assessed outcomes, it is important to note that the use of reliable validated instruments increases the consistency of the results found. The Knee Injury and Osteoarthritis Outcome Score (KOOS) questionnaire was the most widely used assessment tool in the studies included in this review ${ }^{58-60}$. The KOOS has been validated and is based on the Western Ontario and McMaster Universities Osteoarthrtis Index (WOMAC) questionnaire ${ }^{61}$.

Table 1. Methodological classification assessed by PEDro scale.

\begin{tabular}{|c|c|c|c|c|c|c|c|c|c|}
\hline & $\begin{array}{l}\text { Messier } \\
\text { et al. }{ }^{8}\end{array}$ & $\begin{array}{l}\text { Song } \\
\text { et al. }{ }^{56}\end{array}$ & $\begin{array}{l}\text { Diracoglu } \\
\text { et al. }{ }^{1}\end{array}$ & $\begin{array}{l}\text { Hinman, Heywood } \\
\text { and Day }{ }^{27}\end{array}$ & $\begin{array}{l}\text { Lund } \\
\text { et al. }{ }^{2}\end{array}$ & $\begin{array}{l}\text { Trans } \\
\text { et al. }{ }^{29}\end{array}$ & $\begin{array}{l}\text { Chaipinyo and } \\
\text { Karoonsupcharoen }{ }^{55}\end{array}$ & $\begin{array}{l}\text { Jan } \\
\text { et al. }{ }^{13}\end{array}$ & $\begin{array}{l}\text { McKnight } \\
\text { et al. }^{15}\end{array}$ \\
\hline Question 1* & No & Yes & No & Yes & Yes & Yes & Yes & No & Yes \\
\hline Question 2 & Yes & Yes & No & Yes & Yes & Yes & Yes & Yes & Yes \\
\hline Question 3 & Yes & Yes & No & Yes & Yes & Yes & Yes & No & Yes \\
\hline Question 4 & Yes & Yes & Yes & Yes & Yes & Yes & Yes & Yes & Yes \\
\hline Question 5 & No & No & No & No & No & No & No & No & No \\
\hline Question 6 & No & No & No & No & No & No & No & No & No \\
\hline Question 7 & No & No & Yes & Yes & Yes & No & Yes & Yes & No \\
\hline Question 8 & No & No & Yes & Yes & Yes & No & No & Yes & No \\
\hline Question 9 & Yes & No & No & Yes & Yes & Yes & Yes & Yes & Yes \\
\hline Question 10 & Yes & Yes & Yes & Yes & Yes & Yes & Yes & Yes & Yes \\
\hline Question 11 & No & Yes & No & Yes & Yes & Yes & Yes & Yes & Yes \\
\hline Total & 5 & 5 & 4 & 8 & 8 & 6 & 7 & 7 & 6 \\
\hline
\end{tabular}

* Since the score for the first item is on external validity, it is not considered the in the final score (Moseley et al. ${ }^{40}$ ). Question 1: The eligibility criteria were specified; Question 2: The subjects were randomly distributed per group; Question 3: The distribution of the subjects was blind; Question 4: Initially, the groups were similar with respect to prognostic indicators more important; Question 5: All subjects participated in a blind fashion in study; Question 6: All physical therapists who administered the therapy did so in a blinded fashion; Question 7: All evaluators who measured at least one key outcome, they did it blindly; Question 8: Measurements of at least one key outcome was obtained by more than $85 \%$ of the subjects initially distributed by the groups; Question 9: All subjects from which they presented measurements of results received the treatment or the condition of control according to distribution or, became an analysis of the data for at least one of the key outcomes of "intention to treat"; Question 10: The results of statistical comparisons between groups were described for at least one key outcome; Question 11: The study presents both measures of accuracy as measures of variability for at least one key outcome. 


\begin{tabular}{|c|c|c|c|c|}
\hline & 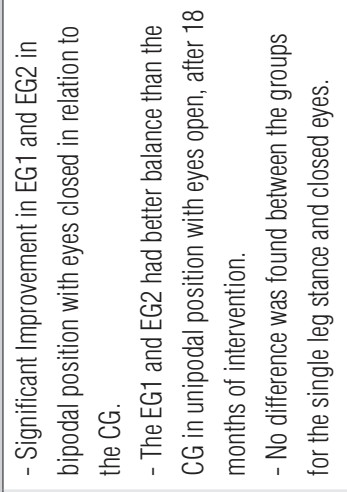 & 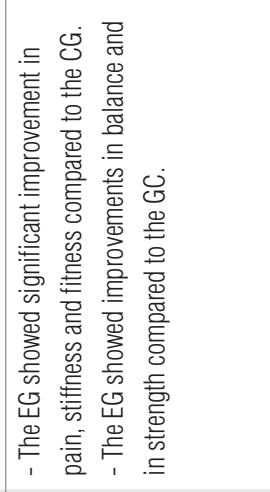 & 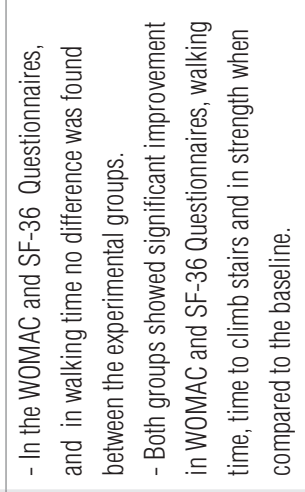 & 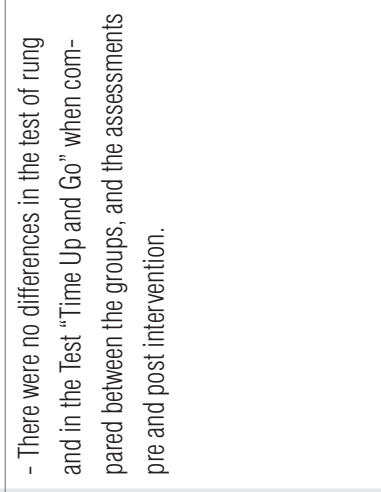 \\
\hline 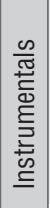 & 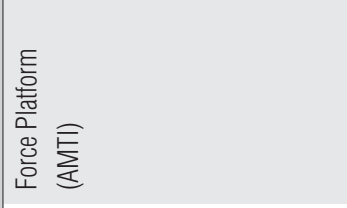 & 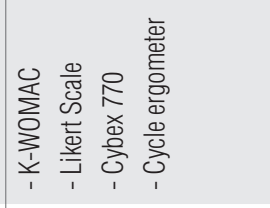 & 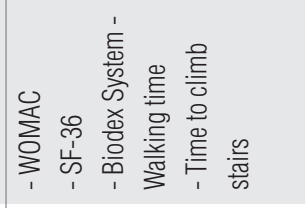 & 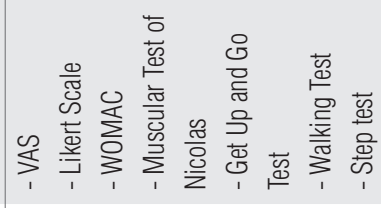 \\
\hline 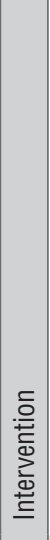 & 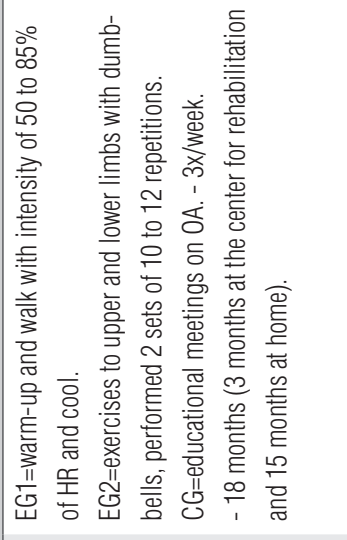 & 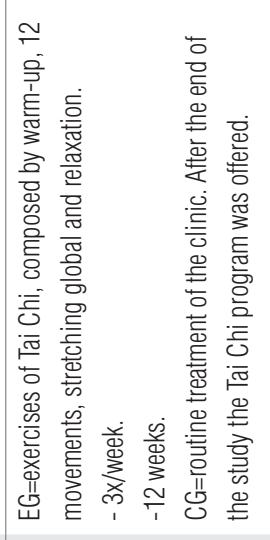 & 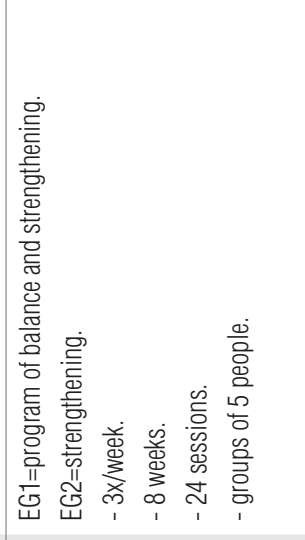 & 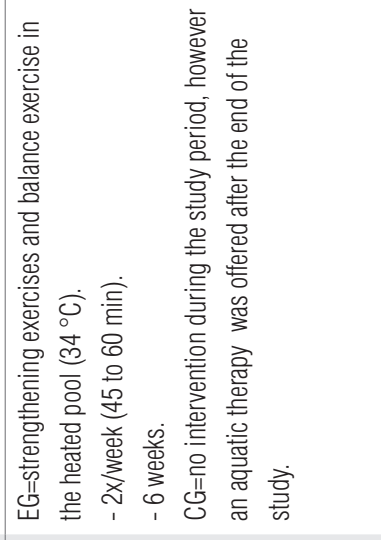 \\
\hline 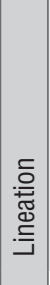 & 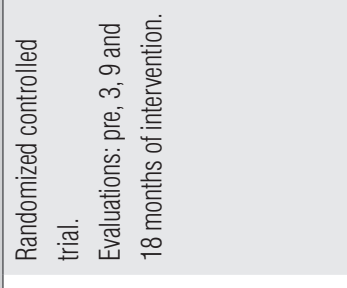 & 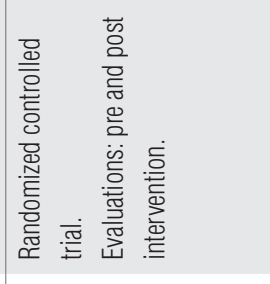 & 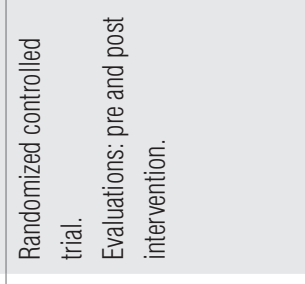 & 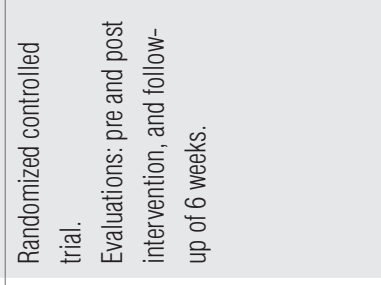 \\
\hline 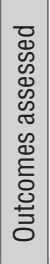 & 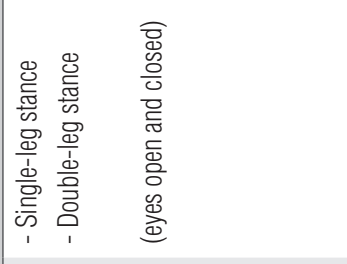 & 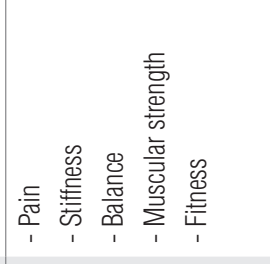 & 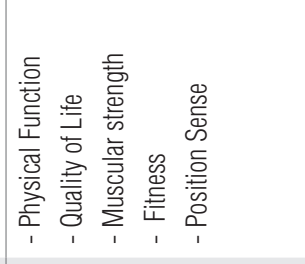 & 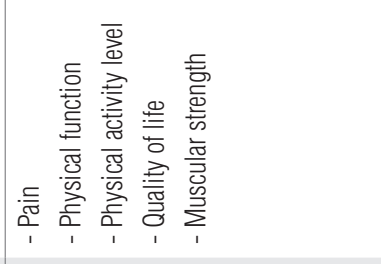 \\
\hline 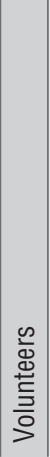 & 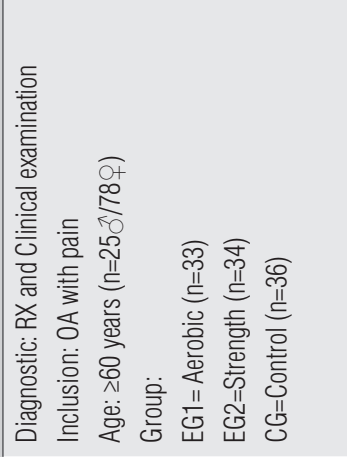 & 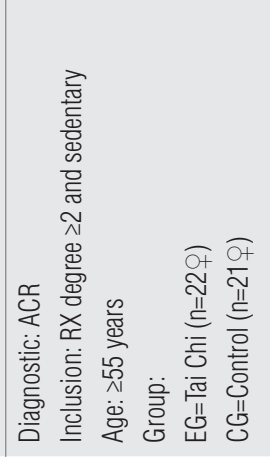 & 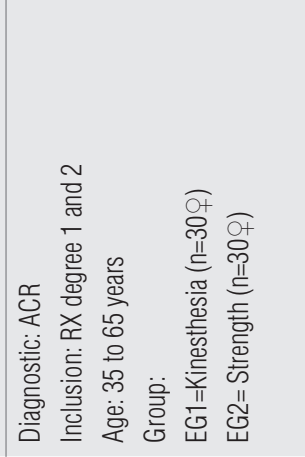 & 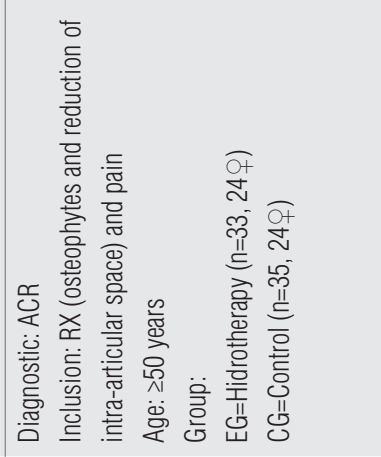 \\
\hline & 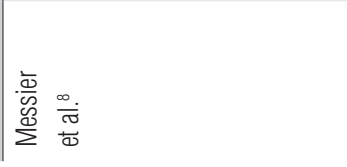 & 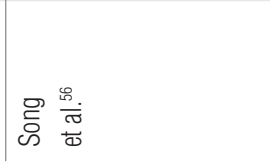 & 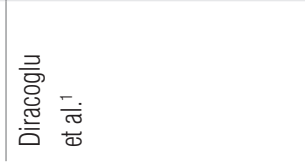 & 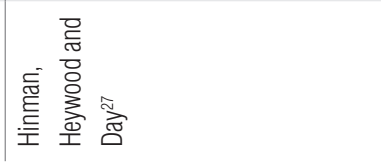 \\
\hline
\end{tabular}




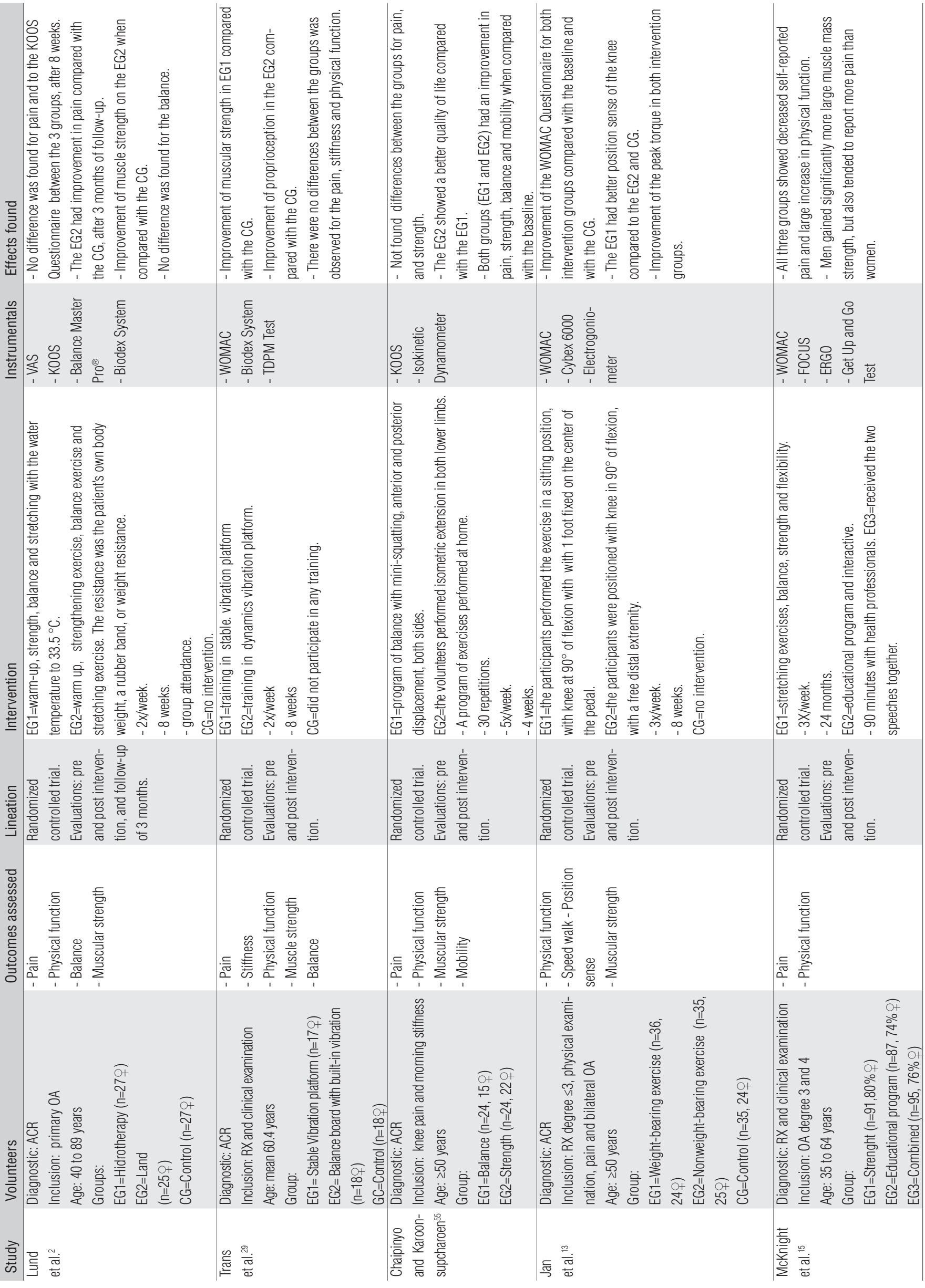


In most of the studies, the OA diagnosis was based on ACR criteria, which consists of clinical and radiographic evaluations, in accordance with the Kellgren and Lawrence Scale ${ }^{62}$ (grades 1 through 4). In clinical trials and observational studies, OA is commonly diagnosed according to ${ }^{15}$ these criteria. However, it should be pointed out that, of the nine included studies, only four reported the OA degree of the subjects included in the sample $e^{1,13,15,56}$.

The representativeness of samples may be considered appropriate, averaging 30 subjects per group; one study used 90 subjects per group ${ }^{15}$. The sample size in most of the studies was calculated to determine the minimum number of subjects necessary for each group $2,8,15,27,29,55$.

All selected studies involved women with OA, and five $e^{8,13,15,27,55}$ contained men in the sample. However, the percentage of women in the groups was always higher, which is compatible with epidemiological data since OA is more prevalent in women ${ }^{14,16}$.

Regarding therapeutic exercise, strength training and aerobic ${ }^{30,63}$ modalities stood out. The aerobic and strength training exercises proposed in Messier et al. ${ }^{8}$, are widely used in patients with knee OA to improve physical conditioning, especially to strengthen the quadriceps, since its weakness may be responsible for complaints of imbalance and pain ${ }^{54,64}$.

Quadriceps strengthening has been shown in several studies to be the key point for controlling pain, physical functioning and quality of life in this population. In addition, this therapeutic approach contributes to improvement in postural sway control, thus improving balance ${ }^{64}$. This has also been demonstrated by Messier et al. ${ }^{8}$, who, using a force platform evaluation after 18 months of intervention, found significant balance improvement compared to controls in groups involved in aerobic and strength exercise in the bipedal position with eyes closed and in the unipedal position with eyes open. However, the appropriate treatment time and session frequency still seem inconclusive in literature due to wide variation among studies.

In a systematic review on knee OA exercise ${ }^{30}$ whose objective was to determine whether therapeutic exercise would be beneficial in terms of joint pain reduction and improvement in physical functioning, it was reported that studies must describe the procedures used in detail, as well as the length of intervention time and the frequency and intensity of training. The lack of a full procedural description prevents the reproduction of clinical findings in new studies.

The results of the studies in this systematic review that used aerobic and strength training exercises demonstrated positive effects for some of the evaluated outcomes, such as pain and stiffness $^{1,2,13}$ and balance ${ }^{1,8}$. However, for the outcome balance, Lund et al. $^{2}$ found no difference. In contrast, in the study by
Diracoglu et al. ${ }^{1}$, in which three times a week for eight weeks one group performed strength training exercises and the other balance exercises associated with strength training, both groups showed significant improvement on the WOMAC, the SF-36, in walking time, time ascending and descending stairs and strength, thus demonstrating the effectiveness of strength and balance exercises for women with knee OA.

Chaipinyo and Karoonsupcharoen ${ }^{55}$ conducted a study comparing a strengthening exercise program with a balance exercise program with a frequency of five times a week for four weeks in women with knee OA and found better quality of life and mobility in the strengthening exercise group than the balance program group.

A survey conducted recently by McKnight et al. ${ }^{15}$, in which a 24-month strength training program, an educational program and an association of both were compared, it was reported that the three groups benefitted with respect to pain and improved physical function, with the men improving in muscular strength more than the women, which demonstrates that an educational program about the dysfunction is also beneficial for patients with knee OA. Similar results have also been reported in other studies ${ }^{65-67}$.

However, conclusions regarding time and frequency of optimal intervention, instruments to be used and adverse effects would be precipitous, since in the evaluated studies, intervention times ranging from four weeks to 18 months were assessed and a variety of instruments were used to assess pain and balance.

Another therapeutic intervention found in this systematic review was hydrotherapy, which provided physiological benefits from both its mechanical and thermal effects. Among these effects, relaxation, analgesia and reduced joint impact should be highlighted, since in this modality muscle spasms, pain and fatigue are reduced and muscle strength and balance are improved due to lack of support points. Thus, the patient is obliged to undergo postural changes that reduce impact and weight unloading on the joints ${ }^{68-70}$.

Two studies analyzed in this systematic review ${ }^{2,27}$ used hydrotherapy as a therapeutic resource. Hinman, Heywood and Day $^{27}$ conducted strengthening and balance exercises twice a week for six weeks and observed significant improvement in physical function, pain, muscle strength and quality of life, but no differences in the Timed Up and Go test. In contrast, Lund et al. ${ }^{2}$, using strengthening, endurance, balance and stretching exercises in groups that exercised in and out of water twice a week for eight weeks, found no difference for pain or balance between groups. Nevertheless, the authors observed that hydrotherapy would provide more benefits to patients with knee OA than to those who performed the protocol out of the water. 
Vibrating platform exercise was used for muscle strengthening ${ }^{71,72}$. Trans et al. ${ }^{29}$ compared three groups: exercise on a stable vibrating platform, exercise on a balance platform with vibration and a control group. Training was administered twice a week for eight weeks, and it was demonstrated that training on a stable platform improved muscular strength, while the training on vibrating balance platform improved proprioception compared to controls.

Thus, studies in this review showed some variation regarding the benefits of therapeutic exercises in relation to time and frequency of treatment. However, in clinical practice, these therapeutic exercises are already used by physical therapists, even without scientific evidence attesting to their effectiveness for this disease. However, based on the results of this review, in which the studies presented high methodological quality, it can be concluded that the involved therapeutic exercises improved the balance of women with knee OA, suggesting that they can lead to safe clinical decisions and provide effective results in the interventions in women with knee OA.

\section{Acknowledgements $: \because$.}

For the financial support of Fundação de Amparo à Pesquisa do Estado de São Paulo (FAPESP), São Paulo, SP, Brazil (PRMSS \#07/07200-4 and AS \#2010/19437-1).

\section{References $: \because$.}

1. Diracoglu D, Aydin R, Baskent A, Celik A. Effects of kinesthesia and balance exercises in knee osteoarthritis. J Clin Rheumatol. 2005;11(6):303-10.

2. Lund H, Weile U, Christensen R, Rostock B, Downey A, Bartels EM, et al. A randomized controlled trial of aquatic and land-based exercise in patients with knee osteoarthritis. J Rehabil Med. 2008;40(2):137-44.

3. Lyytinen T, Liikavainio T, Bragge T, Hakkarainen M, Karjalainen PA, Arokoski JP. Postural control and thigh muscle activity in men with knee osteoarthritis. J Electromyogr Kinesiol. 2010;20(6):1066-74.

4. Coimbra IB, Pastor EH, Greve JMD, Puccinelli MLC, Fuller R, Cavalcanti FS, et al. Consenso brasileiro para o tratamento da osteoartrite (artrose). Rev Bras Reumatol. 2002;42(6):371-4.

5. Bennell KL, Hinman RS, Metcalf BR, Crossley KM, Buchbinder R, Smith M, et al. Relationship of knee joint proprioception to pain and disability in individuals with knee osteoarthritis. J Orthop Res. 2003;21(5):792-7.

6. Poole AR. Biochemical/immunochemical biomarkers of osteoarthritis: utility for prediction of incident or progressive osteoarthritis. Rheum Dis Clin North Am. 2003;29(4):803-18.

7. Brandt KD, Dieppe P, Radin E. Etiopathogenesis of osteoarthritis. Med Clin North Am. 2009;93(1):1-24

8. Messier SP, Royer TD, Craven TE, O'Toole ML, Burns R, Ettinger WH Jr. Long-term exercise and its effect on balance in older, osteoarthritic adults: results from the Fitness, Arthritis, and Seniors Trial (FAST). J Am Geriatr Soc. 2000;48(2):131-8.

9. Felice JC, Costa LFC, Duarte DG, Chahade WH. Elementos básicos de diagnóstico da osteoartrose. Temas de Reumatologia Clínica. 2002;3(3):68-79.

10. Haq I, Murphy E, Dacre J. Osteoarthritis. Postgrad Med J. 2003;79(933):377-83.

11. Miyaguchi M, Kobayashi A, Kadoya Y, Ohashi H, Yamano Y, Takaoka K. Biochemical change in joint fluid after isometric quadriceps exercise for patients with osteoarthritis of the knee. Osteoarthritis Cartilage. 2003;11(4):252-9.

12. Hortobágyi T, Garry J, Holbert D, Devita P. Aberrations in the control of quadriceps muscle force in patients with knee osteoarthritis. Arthritis Rheum. 2004;51(4):562-9.

13. Jan MH, Lin CH, Lin YF, Lin JJ, Lin DH. Effects of weight-bearing versus nonweight-bearing exercise on function, walking speed, and position sense in participants with knee osteoarthritis: a randomized controlled trial. Arch Phys Med Rehabil. 2009;90(6):897-904.

14. Cho HJ, Chang CB, Kim KW, Park JH, Yoo JH, Koh IJ, et al. Gender and prevalence of knee osteoarthritis types in elderly Koreans. J Arthroplasty. 2011 [Epub ahead of print]

15. McKnight PE, Kasle S, Going S, Villanueva I, Cornett M, Farr J, et al. A comparison of strength training, self-management, and the combination for early osteoarthritis of the knee. Arthritis Care Res (Hoboken). 2010;62(1):45-53
16. Srikanth VK, Fryer JL, Zhai G, Winzenberg TM, Hosmer D, Jones G. A meta-analysis of sex differences prevalence, incidence and severity of osteoarthritis. Osteoarthritis Cartilage. 2005;13(9):769-81.

17. Otterness IG, Eckstein E. Women have thinner cartilage and smaller joint surfaces than men after adjustment for body height and weight. Osteoarthritis Cartilage. 2007;15(6):666-72

18. Hanna FS, Wluka AE, Bell RJ, Davis SR, Cicuttini FM. Osteoarthritis and the postmenopausal woman: epidemiological, magnetic resonance imaging, and radiological findings. Semin Arthritis Rheum. 2004;34(3):631-6.

19. Sowers MR, McConnell D, Jannausch M, Buyuktur AG, Hochberg MA, Jamadar DA. Estradiol and its metabolites and their association with knee osteoarthritis. Arthritis Rheum. 2006;54(8):2481-7.

20. Wluka AE, Cicuttini FM, Spector TD. Menopause, oestrogens and arthritis. Maturitas 2000;35(3):183-99.

21. Issa SN, Sharma L. Epidemiology of osteoarthritis: na update. Curr Rheumatol Rep. 2006:8(1):7-15

22. Felson DT. Relation of obesity and of vocational and avocational risk factors to osteoarthritis. $J$ Rheumatol. 2005;32(6):1133-5.

23. Cicuttini F, Forbes A, Morris K, Darling S, Bailey M, Stuckey S. Gender differences in knee cartilage volume as measured by magnetic resonance imaging. Osteoarthritis Cartilage. 1999;7(3):265-71.

24. Maly MR. Abnormal and cumulative loading in knee osteoarthritis. Curr Opin Rheumatol 2008;20(5):547-52.

25. Slemenda C, Heilman DK, Brandt KD, Katz BP, Mazzuca SA, Braunstein EM, et al. Reduced quadriceps strength relative to body weight: a risk factor for knee osteoarthritis in women? Arthritis Rheum. 1998;41(11):1951-9.

26. Lephart SM, Fu FH. Proprioception and neuromuscular control in joint stability. United States of American: Human Kinetics; 2000.

27. Hinman RS, Heywood SE, Day AR. Aquatic physical therapy for hip and knee osteoarthritis: results of a single-blind randomized controlled trial. Phys Ther. 2007;87(1):32-43.

28. Kul-Panza E, Berker N. Pedobarographic findings in patients with knee osteoarthritis. Am J Phys Med Rehabil. 2006;85(3):228-33.

29. Trans T, Aaboe J, Henriksen M, Christensen R, Bliddal H, Lund H. Effect of whole body vibration exercise on muscle strength and proprioception in females with knee osteoarthritis. Knee. 2009;16(4):256-61.

30. Fransen M, McConnell S. Exercise for osteoarthritis of the knee. Cochrane Database Syst Rev. 2008;8(4):CD004376

31. Fransen M, McConnell S, Hernandez-Molina G, Reichenbach S. Exercise for osteoarthritis of the hip. Cochrane Database Syst Rev. 2009;8(3):CD007912. 
32. Fransen M, McConnell S. Land-based exercise for osteoarthritis of the knee: a metaanalysis of randomized controlled trials. J Rheumatol. 2009;36(6):1109-17.

33. Fransen M, McConnell S, Hernandez-Molina G, Reichenbach S. Does land-based exercise reduce pain and disability associated with hip osteoarthritis? A meta-analysis of randomized controlled trials. Osteoarthritis Cartilage. 2010;18(5):613-20.

34. Topp R, Mikesky A, Wigglesworth J, Holt W Jr, Edwards JE. The effect of a 12-week dynamic resistance strength training program on gait velocity and balance of older adults. Gerontologist. 1993;33(4):501-6

35. Lord SR, Castell S. Physical activity program for older persons: effect on balance, strength, neuromuscular control, and reaction time. Arch Phys Med Rehabil. 1994;75(6):648-52.

36. Crilly RG, Willems DA, Trenholm KJ, Hayes KC, Delaquerrière-Richardson LF. Effect of exercise on postural sway in the elderly. Gerontology. 1989;35(2-3):137-43.

37. Maher CG, Sherrington C, Herbert RD, Moseley AM, Elkins M. Reliability of the PEDro Scale for rating quality of randomized controlled trials. Phys Ther. 2003;83(8):713-21.

38. Verhagen AP, de Vet HC, de Bie RA, Kessels AG, Boers M, Bouter LM, et al. The Delphy list: a criteria list for quality assessment of randomized clinical trials for conducting systematic reviews developed by Delphi Consensus. J Clin Epidemiol. 1998;51(12):1235-41.

39. PEDro. The Physiotherapy Evidence Database (PEDro) [acesso em 20 junho 2010]. Disponível em: URL: http://www.pedro.org.au/portuguese

40. Moseley AM, Herbert RD, Sherrington C, Maher CG. Evidence for physiotherapy practice: a survey of the Physiotherapy Evidence Database (PEDro). Aust J Physiother. 2002;48(1):43-9.

41. Maher CG. A systematic review of workplace interventions to prevent low back pain. Aust J Physiother. 2000;46(4):259-69.

42. van Poppel MN, Hooftman WE, Koes BW. An update of a systematic review of controlled clinical trials on the primary prevention of back pain at the workplace. Occup Med (Lond). 2004;54(5):345-52

43. Coury HJCG, Moreira RFC, Dias NB. Evaluation of the effectiveness of workplace exercise in controlling neck, shoulder and low back pain: a systematic review. Rev Bras Fisioter. 2009;13(6):461-79

44. McCarthy CJ, Mills PM, Pullen R, Richardson G, Hawkins N, Roberts CR, et al. Supplementation of a home-based exercise programme with a class-based programme for people with osteoarthritis of the knees: a randomised controlled trial and health economic analysis. Health Technol Assess. 2004;8(46):iii-iv, 1-61.

45. Kraemer WJ, Ratamess NA, Maresh CM, Anderson JA, Volek JS, Tiberio DP, et al. A cetylated fatty acid topical cream with menthol reduces pain and improves functional performance in individuals with arthritis. J Strength Cond Res. 2005;19(2):475-80.

46. Messier SP, Mihalko S, Loeser RF, Legault C, Jolla J, Pfruender J, et al. Glucosamine/chondroitin combined with exercise for the treatment of knee osteoarthritis: a preliminary study. Osteoarthritis Cartilage. 2007;15(11):1256-66.

47. Gremeaux V, Renault J, Pardon L, Deley G, Lepers R, Casillas JM. Low-frequency electric muscle stimulation combined with physical therapy after total hip arthroplasty for hip osteoarthritis in elderly patients: a randomized controlled trial. Arch Phys Med Rehabil. 2008;89(12):2265-73.

48. Higuchi H, Hatayama K, Shimizu M, Kobayashi A, Kobayashi T, Takagishi K. Relationship between joint gap difference and range of motion in total knee arthroplasty: a prospective randomised study between different platforms. Int Orthop. 2009;33(4):997-1000.

49. Chuang SH, Huang MH, Chen TW, Weng MC, Liu CW, Chen CH. Effect of knee sleeve on static and dynamic balance in patients with knee osteoarthritis. Kaohsiung J Med Sci. 2007;23(8):405-11.

50. Carter ND, Khan KM, McKay HA, Petit MA, Waterman C, Heinonen A, et al. Community-based exercise program reduces risk factors for falls in 65- to 75-year-old women with osteoporosis: randomized controlled trial. CMAJ. 2002;167(9):997-1004.

51. Wong YK, Hui E, Woo J. A community-based exercise programme for older persons with knee pain using telemedicine. J Telemed Telecare. 2005;11(6):310-5.

52. Pandya NK, Draganich LF, Mauer A, Piotrowski GA, Pottenger L. Osteoarthritis of the knees increases the propensity to trip on an obstacle. Clin Orthop Relat Res. 2005;(431):150-6.
53. Hortobágyi T, Westerkamp L, Beam S, Moody J, Garry J, Holbert D, et al. Altered hamstringquadriceps muscle balance in patients with knee osteoarthritis. Clin Biomech (Bristol, Avon). 2005;20(1):97-104.

54. Lange AK, Vanwanseele B, Foroughi N, Baker MK, Shnier R, Smith RM, et al. Resistive Exercise for Arthritic Cartilage Health (REACH): a randomized double-blind, sham-exercise controlled trial. BMC Geriatr. 2009;9:1.

55. Chaipinyo K, Karoonsupcharoen 0. No difference between home-based strength training and home-based balance training on pain in patients with knee osteoarthritis: a randomised trial. Aust J Physiother. 2009;55(1):25-30.

56. Song R, Lee EO, Lam P, Bae SC. Effects of tai chi exercise on pain, balance, muscle strength, and perceived difficulties in physical functioning in older women with osteoarthritis: a randomized clinical trial. J Rheumatol. 2003;30(9):2039-44.

57. Holden MA, Nicholls EE, Young J, Hay EM, Foster NE. UK-based physical therapists' attitudes and beliefs regarding exercise and knee osteoarthritis: findings from a mixed-methods study. Arthritis Rheum. 2009;61(11):1511-21.

58. Bellamy N, Buchanan WW, Goldsmith CH, Campbell J, Stitt LW. Validation study of WOMAC: a health status instrument for measuring clinically important patient relevant outcomes to antirheumatic drug therapy in patients with osteoarthritis of the hip or knee. J Rheumatol. 1988;15(12):1833-40.

59. Xie F, Pullenayegum EM, Li SC, Hopkins R, Thumboo J, Lo NN. Use of a disease-specific instrument in economic evaluations: mapping WOMAC onto the EQ-5D utility index. Value Health. 2010;13(8):873-8.

60. Ruyssen-Witrand A, Fernandez-Lopez CJ, Gossec L, Anract P, Courpied JP, Dougados M Psychometric properties of the OARSI/OMERACT osteoarthritis pain and functional impairment scales: ICOAP, KOOS-PS and HOOS-PS. Clin Exp Rheumatol. 2011;29(2):231-7.

61. Roos EM, Toksvig-Larsen S. Knee injury and Osteoarthritis Outcome Score (KO0S) - validation and comparison to the WOMAC in total knee replacement. Health Qual Life Outcomes. 2003;1:17.

62. Kellgren JH, Lawrence JS. Radiological assessment of osteoarthritis. Ann Rheum Dis 1957;16(4):494-502.

63. Rannou F, Poiraudeau S. Non-pharmacological approaches for the treatment of osteoarthritis Best Pract Res Clin Rheumatol. 2010;24(1):93-106.

64. Slemenda C, Brandt KD, Heilman DK, Mazzuca S, Braunstein EM, Katz BP, et al. Quadriceps weakness and osteoarthritis of the knee. Ann Intern Med. 1997;127(2):97-104.

65. Lorig KR, Ritter PL, Laurent DD, Plant K. The internet-based arthritis self-management program: a one-year randomized trial for patients with arthritis or fibromyalgia. Arthritis Rheum. 2008;59(7):1009-17.

66. Coleman S, McQuade J, Rose J, Inderjeeth C, Carroll G, Briffa NK. Self-management for osteoarthritis of the knee: does mode of delivery influence outcome? BMC Musculoskelet Disord. 2010;11:56.

67. Piyakhachornrot N, Aree-Ue S, Putwatana P, Kawinwonggowit V. Impact of an integrated health education and exercise program in middle-aged thai adults with osteoarthritis of the knee. Orthop Nurs. 2011;30(2):134-42.

68. Skinner AT, Thomson AM. Duffield - Exercícios na água. $3^{\mathrm{a}}$ ed. São Paulo: Manole; 1985.

69. Degani AM. Hidroterapia: os efeitos físicos, fisiológicos e terapêuticos da água. Fisioter Mov. 1998;11(1):93-105.

70. Bates A, Hanson N. Exercícios aquáticos. São Paulo: Manole; 1998.

71. Verschueren SM, Roelants M, Delecluse C, Swinnen S, Vanderschueren D, Boonen S. Effect of 6-month whole body vibration training on hip density, muscle strength, and postural control in postmenopausal women: a randomized controlled pilot study. J Bone Miner Res. 2004;19(3):352-9.

72. Roelants M, Delecluse C, Verschueren SM. Whole-body-vibration training increases knee-extension strength and speed of movement in older women. J Am Geriatr Soc. 2004;52(6):901-8. 